\title{
PHAEOCHROMOCYTOMA - A CASE REPORT
}

\author{
Major G. BEVAN \\ M.B., M.R.C.P., D.T.M.\&H., R.A.M.C. \\ Formerly Medical Specialist, British Military Hospital, Dhekelia.*
}

PHAEOCHROMOCYTOMA is an uncommon condition and its diagnosis is not made easier by the fact that the characteristic symptoms are frequently not paroxysmal and may be of long-standing. The classical features have been fully reviewed by MacKeith (1944), Pickering (1955), and Wright (1960), whilst Davies et al. (1963) discuss some of the difficulties of diagnosis. In the following case abdominal pain, weight loss, anorexia, malaise and sweating appeared to point to a more sinister condition than phaeochromocytoma.

\section{Case Report}

The patient, a 37 year old engineer was admitted to the British Military Hospital, Dhekelia, on March 5th, 1963, with severe right sided abdominal pain of sudden onset. He had been unwell for three months with headaches, lassitude, anorexia and heavy, continuous sweating particularly at night. $\mathrm{He}$ had lost 20lb. in weight. Attention had been drawn to his blood pressure during a medical examination four years previously and his wife had noticed that he had had a precordial heave for about a year.

On examination, he looked ill and pale. His temperature was $97^{\circ} \mathrm{F}$ but he was sweating profusely. Blood pressure was $200 / 140 \mathrm{~mm}$. Hg. The apex beat was left ventricular in type and was situated just outside the mid-clavicular line. There was triple rhythm and an aortic ejection murmur could be heard. There was a small haemorrhage in the right fundus. Abdominal palpation revealed minimal epigastric tenderness but no organs or masses could be felt. Forty-eight hours after admission he had an attack of nocturnal dyspnoea. His abdominal pain disappeared soon after admission.

\section{Investigations}

Hb. 102 per cent. WBC $9,200 / \mathrm{cmm}$. P. 74 per cent. L. 21 per cent. Urine normal on ward test and microscopy. Blood urea $30 \mathrm{mg} .100 \mathrm{ml}$. Liver function tests and plasma electrolytes normal. Chest radiograph showed left ventricular enlargement and this was confirmed by the electrocardiogram. Intra-venous pyelogram was normal. Rogitine test was positive on two occasions. Urinary vanilylmandelic acid (VMA) $20 \mathrm{mg}$. per twenty four hours (upper limit of normal $7 \mathrm{mg}$. per twenty four hours); total catecholamines $426 \mu \mathrm{g}$. per twenty four hours (upper limit of normal $200 \mu \mathrm{g}$. per twenty four hours).

The patient was then transferred to The Queen Alexandra Military Hospital, Millbank, and from there to Westminster Hospital. Further investigation included presacral air insufflation which revealed a tumour in front of the left kidney. An aortogram was inconclusive.

Laparotomy was performed by Professor Harold Ellis on May 3rd, 1963, and a tumour measuring three inches by two inches lying over the left kidney was removed (see plate). Histologically the tumour proved to be a benign phaeochromocytoma. Postoperative recovery was uneventful and the patient soon regained his former weight and vitality. His blood pressure, however failed to return to normal. He was re-investigated 


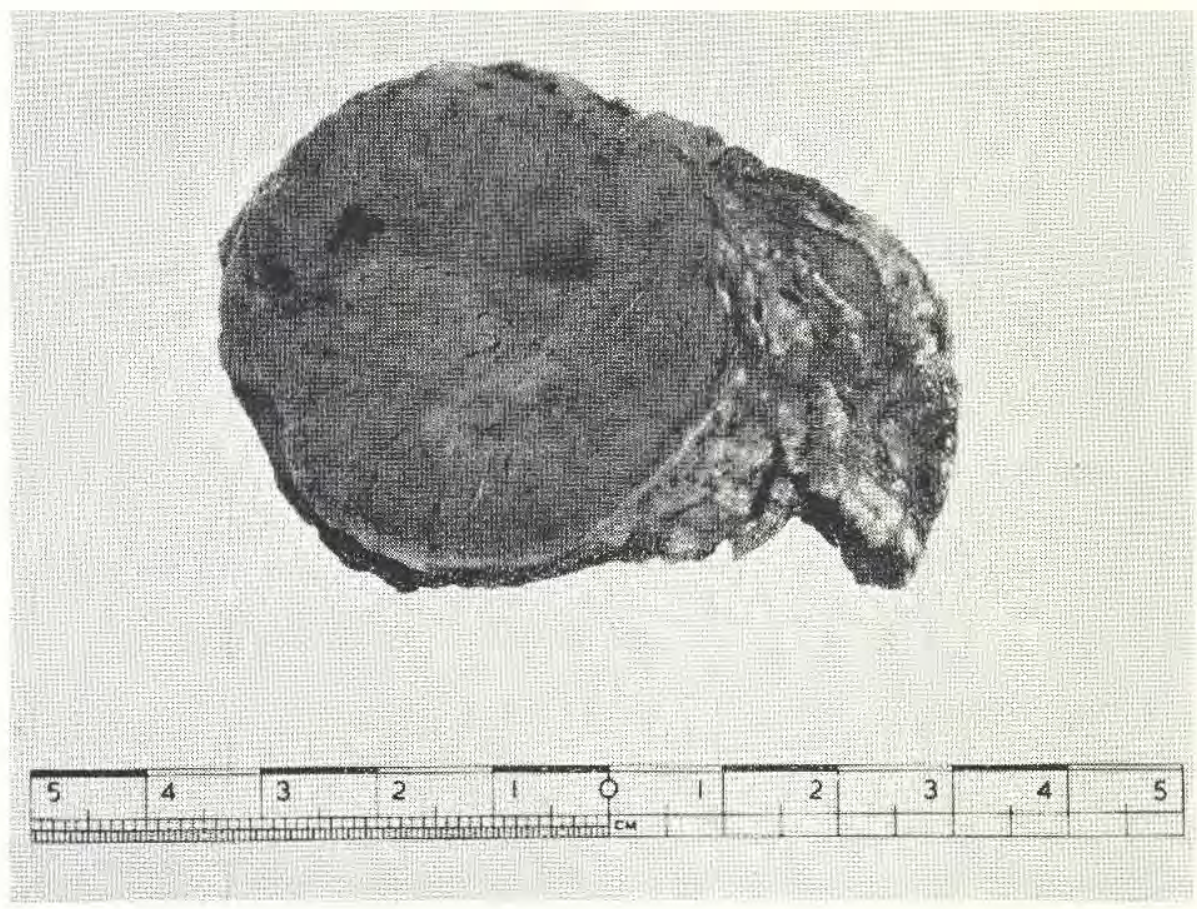

but no evidence of another functioning phaeochromocytoma was found. Satisfactory control of the blood pressure was achieved with reserpine and a year after operation it was $150 / 90 \mathrm{~mm}$. $\mathrm{Hg}$.

\section{Comment}

Abdominal discomfort from a phaeochromocytoma is not uncommon but severe pain is rare. The probable explanation of both symptoms is that haemorrhage occasionally occurs into the tumour and the cut surface usually shows one or two such areas as in the present case. The duration of the pain in this patient was short and suggests that this was the likely cause.

Sustained hypertension is common in patients with a phaeochromocytoma, the classical paroxysmal hypertension being seen only in about one third of all adult cases and even less frequently in children. Furthermore, it may be permanent even when the tumour is successfully removed if irreversible secondary renal changes have taken place. However, bilateral tumours occur in 5-7 per cent of cases and the possibility of another functioning tumour must be excluded by reinvestigation before accepting the maintained hypertension as due to renal changes. It has been suggested by Davies et al. (1963) that the response to the phentolamine test may be a guide to the fall in blood pressure to be expected after operation, a negative phentolamine test indicating that the level of blood pressure at the time of the test is independent of circulating catecholamines and will not be reduced permanently by removal of the tumour. This was not so in the present patient 
in whom the response to the test was unequivocally positive and the resultant blood pressure reading was in the normal range $-140 / 90 \mathrm{~mm}$. Hg. He did give a family history of hypertension and this might be a factor in maintaining the blood pressure. In this context it is interesting to speculate on whether or not another member of the family might have suffered from a phaeochromocytoma, since this condition is occasionally familial.

\title{
Summary
}

A phaeochromocytoma presenting as an acute abdomen with sustained hypertension is described. Subsequent laparotomy confirmed the diagnosis and the tumour was removed. The blood pressure failed to return to normal following operation and the possible reasons for this are discussed.

MACKEITH, R. (1944). Brit. Heart. J. 6, 1.

\section{REFERENCES}

PICKeRING, G. W. (1955). High Blood Pressure. London. Churchill.

Wright, J. T. (1960). Postgrad. med. J. 36, 165.

Davies, D. M., Ross, J, H., Richardson, J. E. and Brown, A. I. P. (1963). Postgrad. med. J. $39,337$.

\section{Trucial Oman Scouts}

To all ex Scouts. The Scouts now meet during opening hours in the Glass House Stores, 55 Brewer Street, W.1. just off Piccadilly Circus. Any Scouts or ex Scouts when in London are invited to see the Manager Mr. A. R. Arlett and sign the visitors book to contact other Scouts in London.

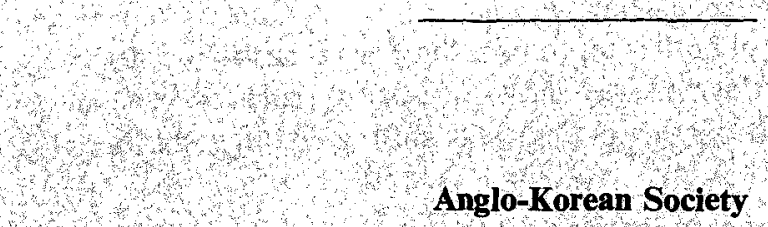

The Presidents of this Society, H.E. The Korean Ambassador and LieutenantGeneral Sir William Pike, have brought it to the notice of those units and corps who vere represented in Korea.

Publishing a bulletin on Korean affairs and arranging lectures, films and social occasions as well as supporting charitable causes in Korea are amongst the ends pursued.

Ordinary membership at $11-1-0 \mathrm{~d}$ per annum is available, for which application should be made to:

\author{
Mr. W. D. Reeve, \\ Flat 2, 24 Lewes Crescent, \\ Brighton, Sussex.
}

